\title{
Bone Scintigraphy in Poststreptococcal Periostitis With Dysproteinemia
}

\author{
Sophie Bourgeois, MD, * Willy Peetermans, MD, PhD, $†$ Nathalie Noppe, $M D, \neq$ \\ Karolien Goffin, $M D, P h D,{ }^{*}$ and Olivier Gheysens, $M D, P h D *$
}

\begin{abstract}
A 39-year-old man presented with severe bone pain in the tibiae and forearms in the wake of a poststreptococcal sepsis complicated with pneumonia and erysipelas 4 months earlier. Bone scintigraphy was indicative of periostitis of the tibia, ulna, and radius bilaterally, and in combination with the increased inflammatory parameters and dysproteinemia, the diagnosis of Goldbloom syndrome was made. Goldbloom syndrome is an idiopathic periosteal hyperostosis associated with dysproteinemia and elevated inflammatory parameters. Although it has only been described in children/ adolescents, this case illustrates that, in the specific clinical and biochemical setting, it should also be considered in adults.
\end{abstract}

Key Words: bone scintigraphy, poststreptococcal periostitis, dysproteinemia, Goldbloom syndrome

(Clin Nucl Med 2018;43: e366-e367)

Received for publication April 25, 2018; revision accepted June 11, 2018.

From the Departments of *Nuclear Medicine and Molecular Medicine, $†$ Internal

Medicine, and $\$$ Radiology, University Hospitals Leuven, Leuven, Belgium. Conflicts of interest and sources of funding: none declared.

Correspondence to: Sophie Bourgeois, MD, Department of Nuclear Medicine and Molecular Medicine, University Hospitals Leuven, Herestraat 49, 3000, Leuven, Belgium. E-mail: sophie.bourgeois@uzleuven.be.

Copyright (C) 2018 Wolters Kluwer Health, Inc. All rights reserved.

ISSN: 0363-9762/18/4310-e366

DOI: $10.1097 /$ RLU.0000000000002208

\section{REFERENCES}

1. Goldbloom RB, Stein PB, Eisen A, et al. Idiopathic periosteal hyperostosis with dysproteinemia. A new clinical entity. N Engl J Med. 1966;274:873-878.

2. Grogan DP, Martinez R. Transient idiopathic periosteal reaction associated with dysproteinemia. J Pediatr Orthop. 1984;4:491-494.

3. Santos S, Estanqueiro P, Salgado M. Goldbloom's syndrome - a case report. Acta Reumatol Port. 2013;38:51-55.

4. Gardiner J, Zauk A, Donchey S, et al. Prostaglandin-induced cortical hyperostosis. Case report and review of the literature. J Bone Joint Surg Am. 1995;77: 932-936.

5. Melhem R, Najjar S, Khachadurian A. Cortical hyperostosis with hyperphosphatemia: a new syndrome? J Pediatr. 1970;77:986-990.

6. Mikati M, Melhem R, Najjar S. The syndrome of hyperostosis and hyperphosphatemia. J Pediatr. 1981;99:900-904.

7. Cameron B, Laxer R, Wilmot D, et al. Idiopathic periosteal hyperostosis with dysproteinemia (Goldbloom's syndrome): case report and review of the literature. Arthritis Rheum. 1987;30:1307-1312.

8. Talab YA, Mallouh A. Hyperostosis with hyperphosphatemia: a case report and review of the literature. J Pediatr Orthop. 1988;8:338-341.

9. Kuwashima S, Nishimura G, Harigaya A, et al. A young infant with Goldbloom syndrome. Pediatr Int. 1999;41:110-112. 


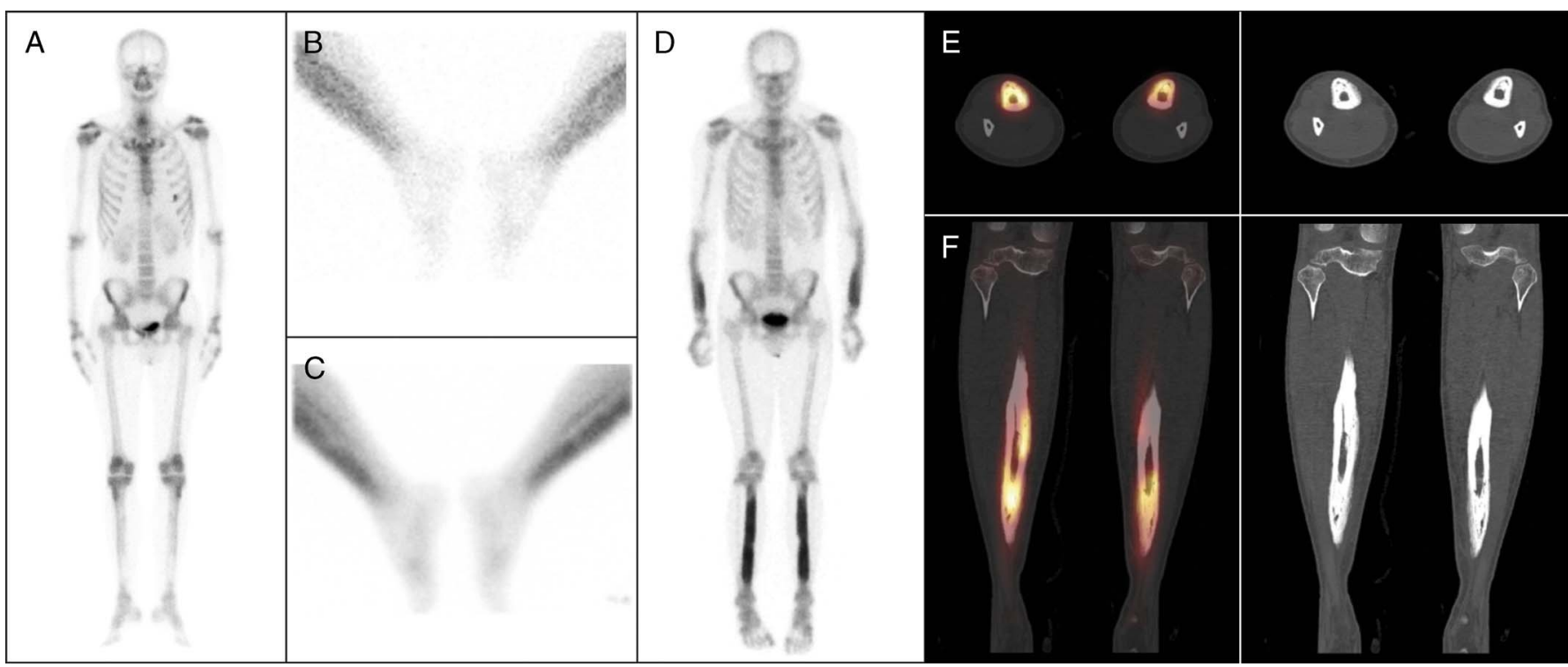

FIGURE 1. A 39-year-old man was admitted to the hospital with Streptococcus pyogenes septicemia causing pneumonia and erysipelas of the right arm 3 weeks after a circumcision. Adequate antibiotic treatment (ampicillin and clindamycin) and supportive care were started with good response, but during admission, he started complaining of severe tibial pain bilaterally while standing. Because of clinical suspicion of periostitis, bone scintigraphy was performed but did not show any significant abnormalities (A). In addition to bone pain, clinical exam revealed enlarged inguinal lymph nodes, and a subsequent FDG-PET/CT exam was performed to exclude malignancy, demonstrating hypermetabolic iliac, inguinal, and axillary lymph nodes. Histopathological analysis of an inguinal lymph node revealed only reactive lymphatic tissue. The patient was discharged, but the pretibial pain with dysesthesia persisted; 3 to 4 months later, similar complaints occurred in both forearms for which he consulted the internal medicine department. Extensive laboratory analysis revealed an increased C-reactive protein (30.5 mg/L; reference, $<5)$ and dysproteinemia with a slightly increased alfa-2-globulin $(10.9 \mathrm{~g} / \mathrm{L}$; reference, 5.1-8.5) and gamma globulin (14.8 g/L; reference, 8.0-13.5). A repeat 3-phase bone scintigraphy showed diffusely increased activity in both tibiae during the flow (B) and blood pool phase (C). The whole-body scan demonstrated diffusely increased (peri)cortical activity in both tibiae, as well as in ulna and radius of both forearms (D). SPECT-CT confirmed the increased cortical activity that corresponded to thick periosteal new bone formation of the tibial diaphysis (E, F). Therapy with nonsteroidal anti-inflammatory drugs and corticosteroids was started but terminated early because of little effect on the fluctuating pain. A spontaneous further recuperation was expected, and indeed, the pain disappeared completely 3 months later. The diagnosis of Goldbloom syndrome was established, based on medical history (poststreptococcal sepsis), laboratory results, and periostitis on bone scintigraphy. Goldbloom syndrome was first described in 1966 by Goldbloom et al and is an idiopathic (although most cases involve a previous streptococcal infection) periosteal hyperostosis associated with dysproteinemia and elevated inflammatory parameters in children and adolescents. ${ }^{1-3}$ A similar syndrome with cortical hyperostosis has been described in infants who received prostaglandin $\mathrm{E}$ for the treatment of congenital heart defects. ${ }^{4}$ The bone pain complaints of patients are often disproportionate to the clinical findings. The periostitis in Goldbloom syndrome mostly involves the long bones, and bone scintigraphy can aid in the differential diagnosis of the pain symptoms, which includes lymphoproliferative disease (which was ruled out by FDG-PET/CT in this case), malignant bone disease, and osteomyelitis. 2,3,5-9 Treatment consists of nonsteroidal anti-inflammatory drugs and corticosteroids, and a spontaneous recuperation, albeit over a couple of months, can be expected, as shown in this case. ${ }^{3}$ Although Goldbloom syndrome has only been reported in children and adolescents, this entity should be included in the presence of the appropriate clinical and biochemical setting in adults. 